\title{
Design of Stiffness for Air Spring Based on ABAQUS
}

\author{
Hongguang Li, ${ }^{1,2}$ Konghui Guo, ${ }^{1}$ Shuqi Chen, ${ }^{3}$ Wei Wang, ${ }^{4}$ and Fuzhong Cong ${ }^{4}$ \\ ${ }^{1}$ State Key Laboratory of Automobile Simulation and Control, Jilin University, Changchun 130022, China \\ ${ }^{2}$ Aircraft Dynamics Department, Aviation University of Air Force, Changchun 130022, China \\ ${ }^{3}$ KH Automotive Technologies, Changchun Co. Ltd., Changchun 130012, China \\ ${ }^{4}$ Department of Foundation, Aviation University of Air Force, Changchun 130022, China
}

Correspondence should be addressed to Konghui Guo; guokonghui@aclu.jlu.edu.cn

Received 19 July 2013; Accepted 8 September 2013

Academic Editor: Song Cen

Copyright (C) 2013 Hongguang Li et al. This is an open access article distributed under the Creative Commons Attribution License, which permits unrestricted use, distribution, and reproduction in any medium, provided the original work is properly cited.

In this paper, an axisymmetric finite element (FE) model of an air spring was carried out with the software ABAQUS to design its target vertical stiffness. The bellows was simulated by the reinforced surface element. The compressed gas in the cavity of the air spring was represented by the hydrostatic fluid element. The target stiffness is obtained by modifying the valid area of the cross section. At last, the results of experiment coincided well with the simulation data. The study shows that the static stiffness of air spring is sensitive to the effective area of the cross section. The conclusion has certain practical significance for the design and the optimization of the same kind of air spring.

\section{Introduction}

An air spring is increasingly used as a spring component of suspension system for commercial and personal vehicles. The main advantages of the air spring against other metal springs are: capability of stiffness regulation, almost constant resonant frequency at different loads, and automatic height adjustment. So, these can greatly enhance stability and comfort of vehicles.

Vertical stiffness is an important characteristic parameter of an air spring. It directly relates to the performance of the air spring. The traditional design method is based on the thermodynamics theory. Using a graphical method and related assumptions, the empirical formulas of various air springs [1-4] can be deduced. But, the accuracy of this method is too low due to the complex geometry, the structure, and the material. Currently, the stiffness of an air spring is obtained mostly through experiments. Although the accuracy of the experimental method is high, it is still at the expense of time and money, and it is too difficult to optimize the structure. In recent years, the finite element method has been used to calculate and analyze the air spring [5-7]. The influences of factors, such as capsule shape, cord angle, cord interval, and inflation pressure, on the elastic performance of air spring were studied.
The purpose of this work is to enable optimized air spring to reach target stiffness. We decided to use FE analysis to determine the effective area of the cross section of the air spring. The validity of the stiffness design is demonstrated by the experiment.

\section{Finite Element Analysis}

2.1. Structure Analysis. The air spring is composed of an upper plate, a rubber composite bellows, a piston, and a bumper (see Figure 1). The bellows is made of composite material consisting of an inner rubber sealing layer, a layer of nylon corded rubber material used for reinforcement, and the outer rubber layer used for protection from surroundings. The interior of the air spring is filled with compressed air which offers carrying capacity and, by its compression and expansion, responds to changing loads.

2.2. FE Model. At the beginning, all parts of the air spring are unloaded, and the air spring is in fully extended state. The upper plate and skirt are fixed. Then, the pressure load is imposed on the inner surface of the bellows. After that, the piston moves in the axial direction of the air spring, and the working stroke is set to $100 \mathrm{~mm}$ (see Figure 2). 


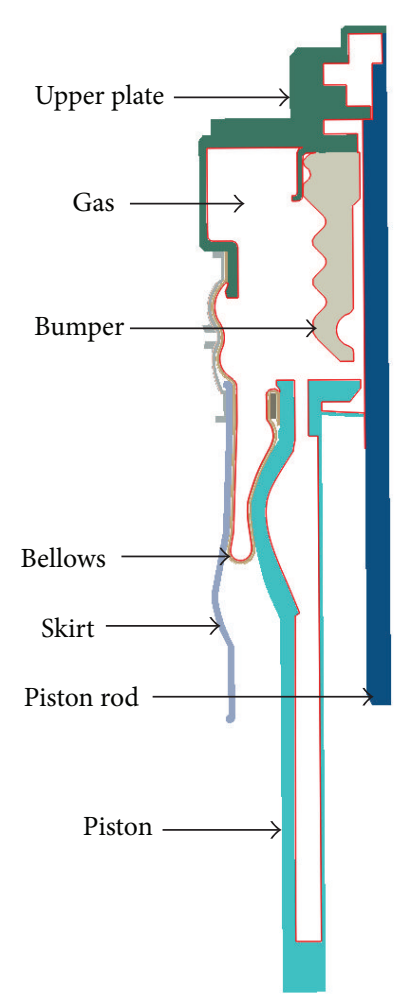

FIGURE 1: Axisymmetric model of air spring structure.

During operation, the bellows rolls over the piston. Therefore, the mechanical behavior of an air spring embraces not only geometric nonlinearity and material nonlinearity but also boundary conditions nonlinearity. Check the general contact option in the simulation. To simulate the rubber material, the Mooney-Rivlin constitutive model is adopted. The fiber-reinforced rubber composite can be assumed as an elastic, orthotropic, and homogeneous material. The Mooney-Rivlin parameters of the rubber, $c_{10}$ and $c_{01}$, are determined by the Shore hardness measured through experiments [8]. The parameters of the model are listed in Table 1.

Fluid element named FAX2 is used to simulate the air. Rebar-reinforced surface element and 4-node bilinear axisymmetric solid element, named CAX4R and SFMAX1, respectively, are used to simulate the bellows. The other parts of the air spring are modeled only by CAX4R. There are 5463 nodes, 1002 FAX2 elements, 4183 CAX4R elements, and 512 SFMAX1 elements in the whole FE model.

2.3. Analysis Results. By simulation, we obtained the relations of pressure, volume, force and displacement with respect to time (see Figure 3).

Figure 4 shows the derivative curve of force versus displacement, namely, stiffness curve of air spring. There exists a static equilibrium position, for the air spring. Above the equilibrium position the air spring is compressed and so its displacement is negative. When the displacement equals $-21 \mathrm{~mm}$, the stiffness increases suddenly since the piston is in contact with the bumper. Bellow the equilibrium position,
TABLE 1: Model parameters.

\begin{tabular}{lcc}
\hline Steel & & \\
Elastic modulus & $2.1 e+5$ & $(\mathrm{MPa})$ \\
Density & $7.8 e-9$ & $\left(\mathrm{t} / \mathrm{mm}^{3}\right)$ \\
Poisson ratio & 0.3 & \\
Rubber & & \\
$\quad$ Shore hardness & 55 & $\mathrm{HA}$ \\
$\quad$ Mooney-Rivlin parameters $c_{01}$ & 0.1 & \\
Mooney-Rivlin parameters $c_{10}$ & 0.5 & \\
Rebar properties & & \\
$\quad$ Material & steel & $\left(\mathrm{mm}{ }^{2}\right)$ \\
Area per Bar & 0.385 & $\mathrm{~mm}$ \\
Spacing & 7.5 & $\left({ }^{\circ}\right)$ \\
Orientation angle & 0 & \\
Air & & $(\mathrm{J} / \mathrm{kg} \mathrm{K})$ \\
$\quad$ Gas constant & 287 & $(\mathrm{~K})$ \\
$\quad$ Temperature & $-273.15+25$ &
\end{tabular}

the air spring is in rebound state. In actual work, the air spring maximum rebound height measured at the largest extremity is around $45 \mathrm{~mm}$. In other words, the data beyond the maximum rebound height is useless. As seen in Figure 4, the stiffness curve of the air spring is nonlinear. In low stiffness area, the stiffness is about $15 \sim 25 \mathrm{~N} / \mathrm{mm}$. In high stiffness area, the stiffness is about $35 \sim 45 \mathrm{~N} / \mathrm{mm}$. But, in this project, the target stiffness is $20 \pm 5 \mathrm{~N} / \mathrm{mm}$ in low stiffness areas and $50 \pm 5 \mathrm{~N} / \mathrm{mm}$ in high stiffness areas.

2.4. Modifying and Analyzing Again. To obtain the target stiffness, we took the formula of the air spring stiffness as a reference,

$$
C_{0}=\left(p_{0}-1\right) \frac{d A}{d f}+K p_{0} \frac{A^{2}}{V_{0}}
$$

where $C_{0}$ represents the vertical static stiffness; $p_{0}$ and $V_{0}$ are the inner air pressure and the air volume at static equilibrium position, respectively; $d f$ is a small amount of axial deformation; $K$ is the variable factor to consider different vibration conditions; and $A$ is the effective area of cross section. $A=$ $(\pi / 4) D^{2} ; D$ is the effective diameter of the air spring [9]. We noticed that $p, V, A$, and $f$ all vary with the piston movement. We also considered that the rate of the effective area of cross section, $d A / d f$, is relatively easy to control in the structure design.

Figure 5 is the illustration of modifying the structure. Through changing the shape, size, or slope of the skirt from A to $B$ and the piston from $C$ to $D$, the effective area of the cross section is adjusted. After each adjustment, the process of finite element analysis is carried out again. At last, we got the satisfactory results. As shown in Figure 6, perfect stiffness curve was achieved. According to the model, the air springs in rear suspension were produced. 


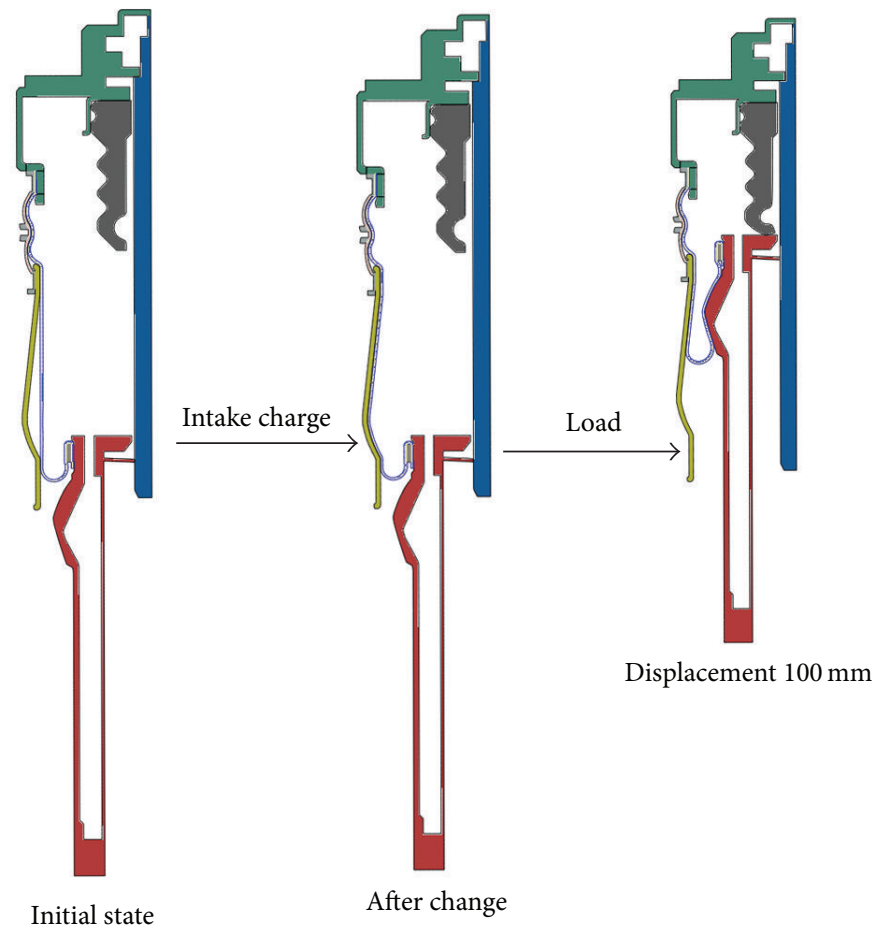

FIGURE 2: Nonlinear analysis steps.

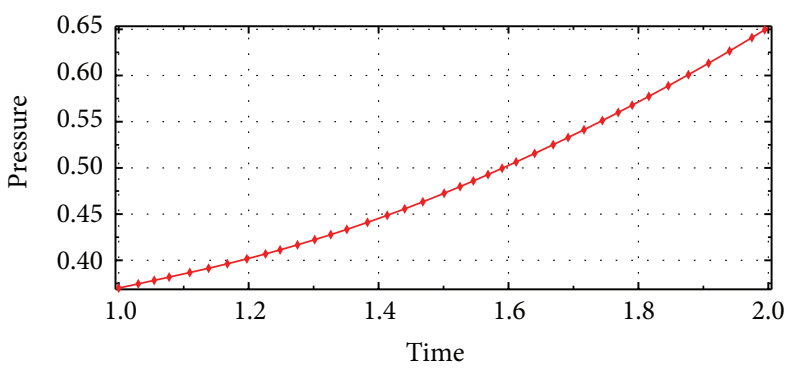

$\rightarrow$ PCAV N: 50000 NSET CAVITY

(a)

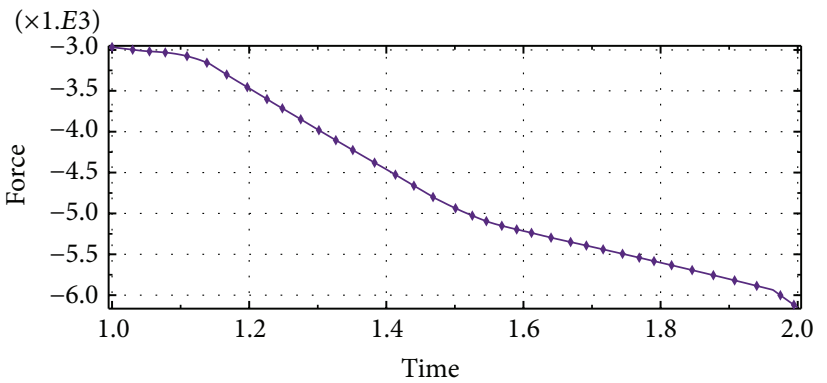

$\rightarrow$ RF2 N: 6000 NSET UP

(c)

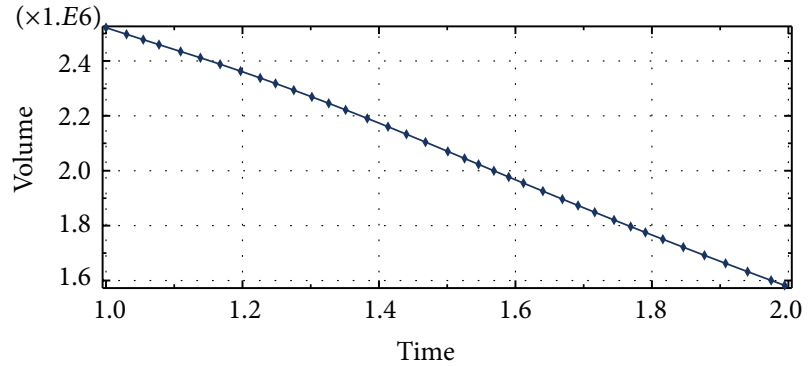

$\rightarrow \quad$ CVOL N: 50000 NSET CAVITY

(b)

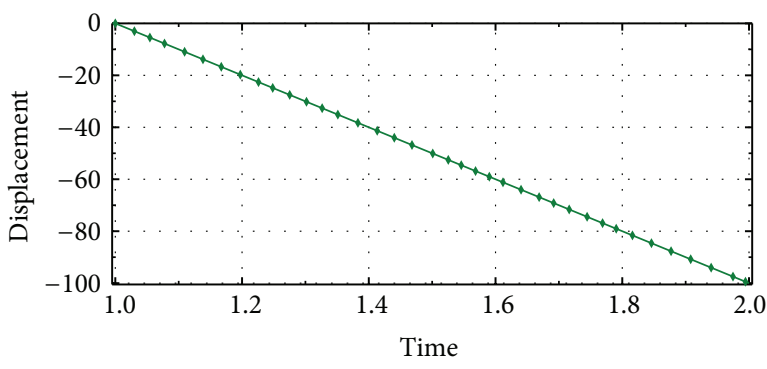

$\rightarrow$ U2 N: 6000 NSET UP

(d)

FIGURE 3: Relations of pressure, volume, force, and displacement versus time. 


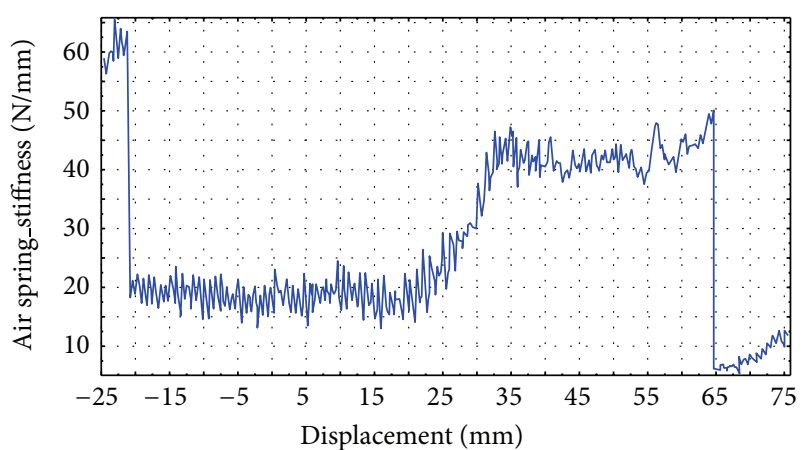

FIGURE 4: Static stiffness before modifying the structure.

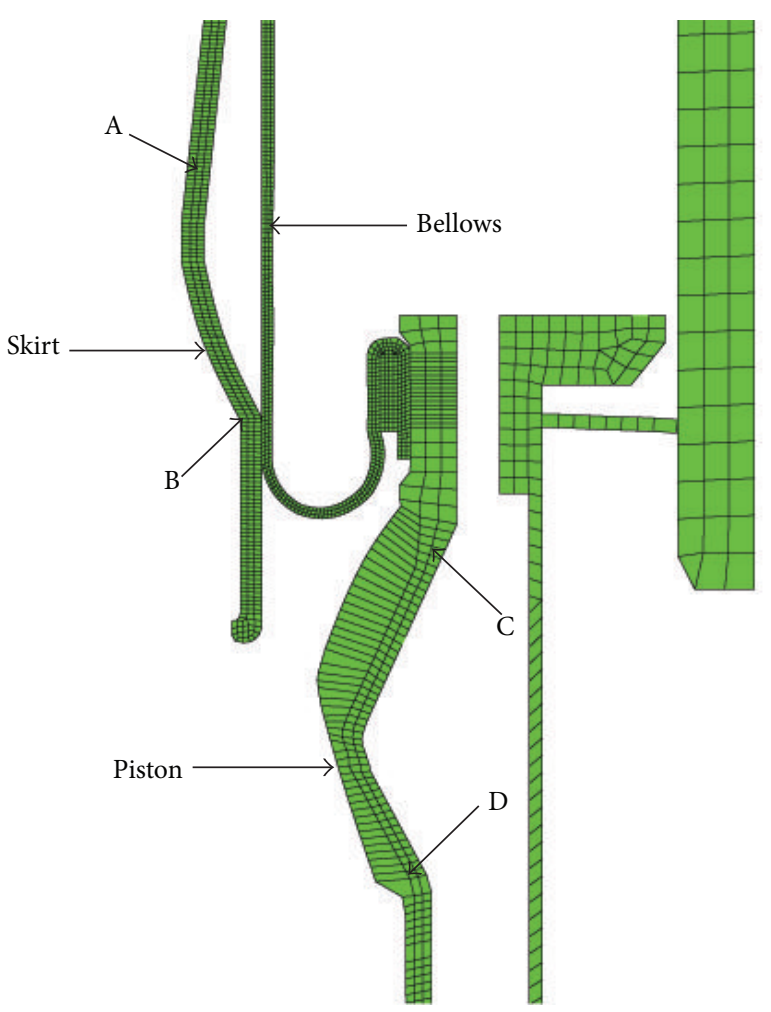

FIgURE 5: Illustration of modifying the structure.

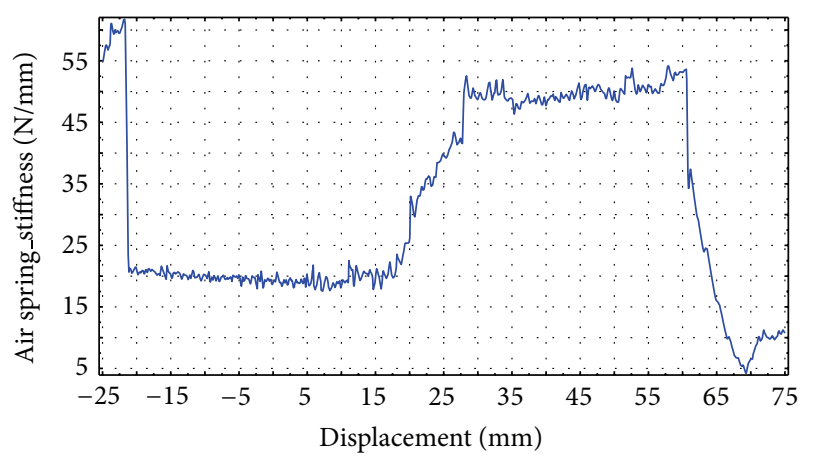

FIGURE 6: Static stiffness after modifying the structure.

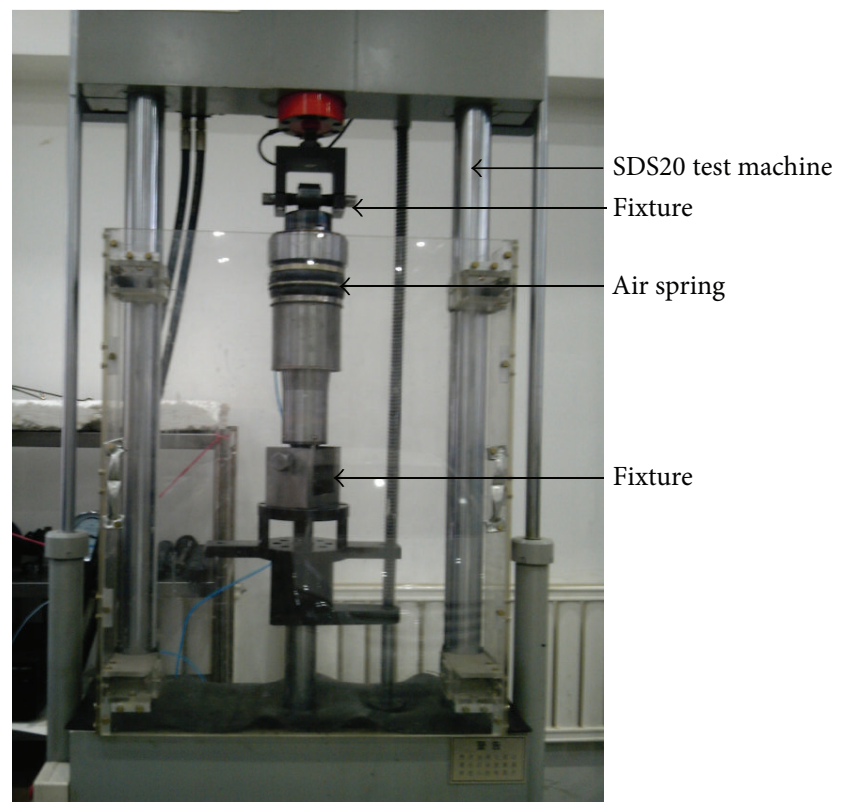

FIGURE 7: Static stiffness experiment of air spring.

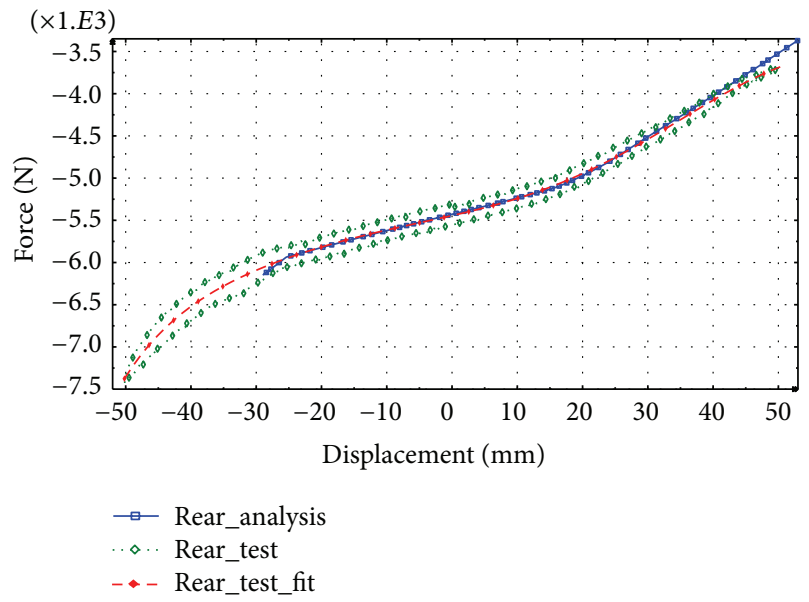

FIGURE 8: Comparison of the simulation results and the experiment results.

\section{Experiment}

In order to verify the analysis results, static stiffness experiment of the air spring was made. At First, clamp the air spring on the SDS20 static stiffness test machine (see Figure 7). Then, inflate the air spring and make it reach the design load, $5450 \mathrm{~N}$. With the loading rate, $2 \mathrm{~mm} / \mathrm{s}$, the total displacement of the air spring reaches $\pm 50 \mathrm{~mm}$. Record the data reflecting the relations between the force and displacement.

In Figure 8, "Rear_analysis" and "Rear_test" stand for the simulation and test about the air spring in rear suspension, respectively. "Rear_test_fit" represents the fitting test curve. There is a little difference in the relation curve of force and displacement. In other words, the simulation results coincided well with the experiment results. 


\section{Conclusion}

(1) The target stiffness of the air spring was implemented by the finite element analysis based on ABAQUS. This means that using the nonlinear finite element software ABAQUS to simulate the stiffness of air spring is feasible. Due to avoiding the repetitious experiments, money and time are saved.

(2) The process of finite element analysis indicates that the static stiffness of air spring is sensitive to the effective area of the cross section. In general, the modification of the air spring structure, such as piston or skirt, is easy to realize.

\section{References}

[1] Z. Jianwen, Z. Dejun, L. Yi et al., "Survey of automotive air spring suspension system," Journal of Highway and Transportation Research and Development, no. 12, pp. 151-155, 2002 (Chinese).

[2] Z. Hong-Lun and Z. Guang-Shi, "A study on nonlinear lateral stiffness of air spring for high speed railway," Journal of the China Railway Society, vol. 21, no. 5, pp. 30-33, 1999 (Chinese).

[3] K. Toyofuku, C. Yamada, T. Kagawa, and T. Fujita, "Study on dynamic characteristic analysis of air spring with auxiliary chamber," JSAE Review, vol. 20, no. 3, pp. 349-355, 1999.

[4] D. N. Wormley, D. P. Garg, and H. H. Richardson, "A comparative study of nonlinear and linear performance of vehicle air cushion suspensions using bond graph models," Journal of Dynamic Systems, Measurement and Control, vol. 94, no. 3, pp. 189-197, 1972.

[5] S. Oman, M. Fajdiga, and M. Nagode, "Estimation of air-spring life based on accelerated experiments," Materials and Design, vol. 31, no. 8, pp. 3859-3868, 2010.

[6] G. Tai-Ping, H. Lin, and Z. Ying-Long, "Composite finite element approach for dynamic stiffness calculation of bellows type air spring," Journal of Vibration and Shock, vol. 29, no. 8, pp. 221223, 2010 (Chinese).

[7] W. Shan-Yue and H. Ying-Yun, "Analysis of air-sping's stiffness by finite element method," Journal of Naval University of Engineering, vol. 13, no. 6, pp. 94-98, 2001 (Chinese).

[8] Z. Liang and X. Fei-Xiong, "A method to determine the materials coefficient of rubber Mooney-Rivlin model," Machinery, no. 7, pp. 38-40, 2008.

[9] W. Wang-Yu, Auto Design, Machine Press, Shanghai, China, 4th edition, 2004. 


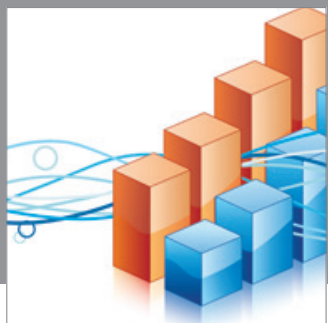

Advances in

Operations Research

mansans

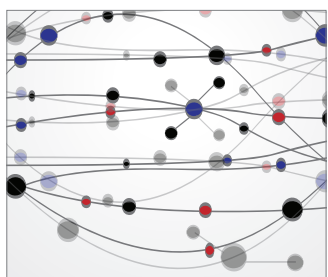

The Scientific World Journal
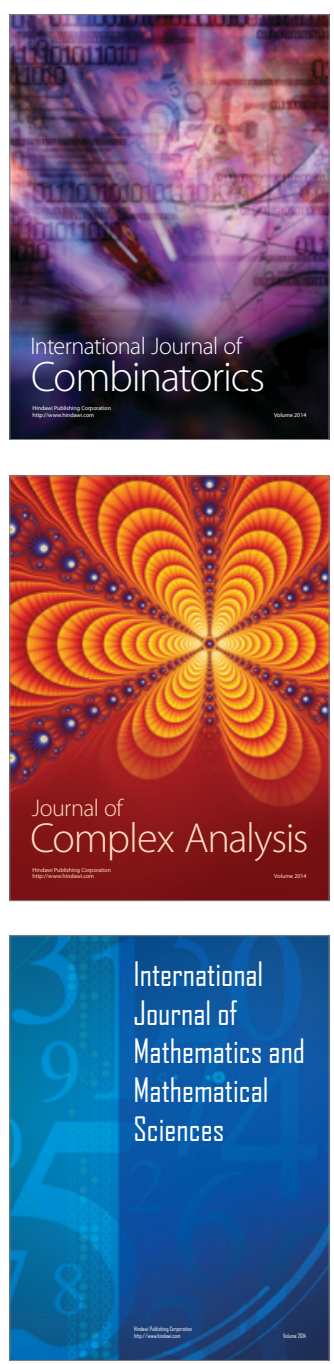
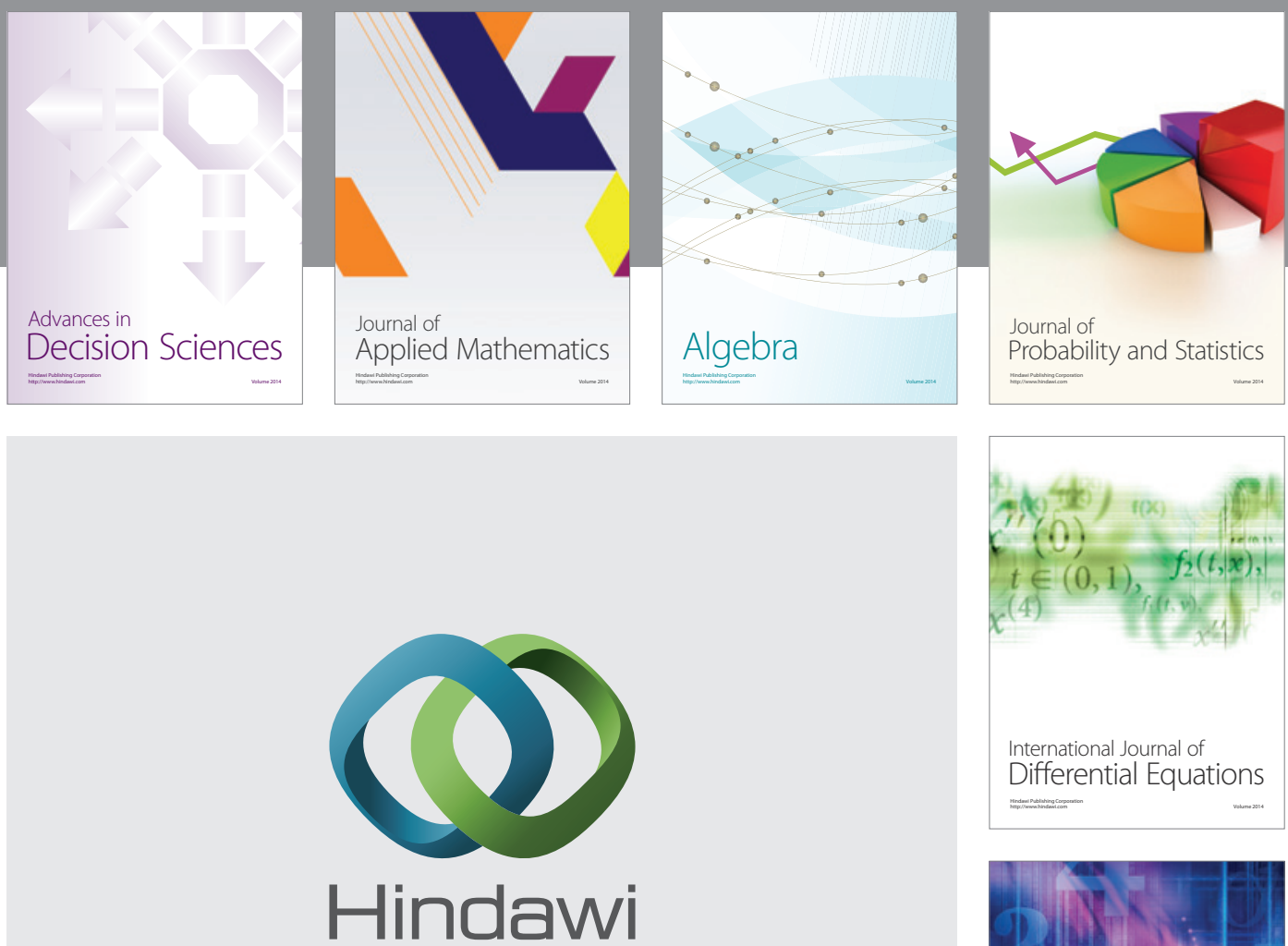

Submit your manuscripts at http://www.hindawi.com
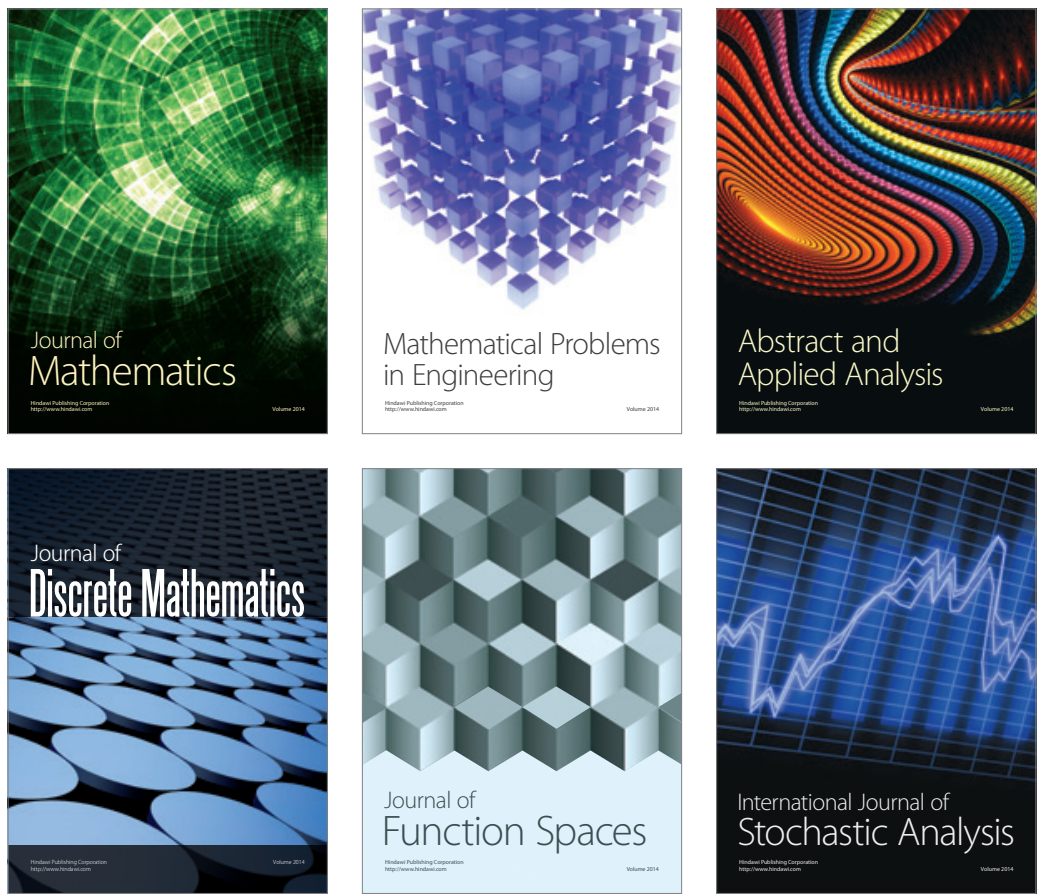

Journal of

Function Spaces

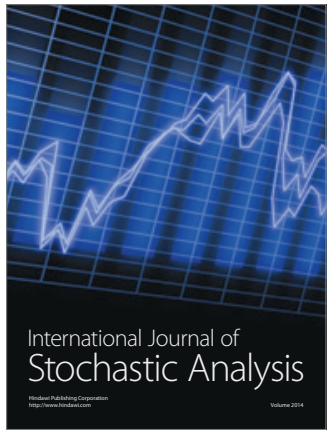

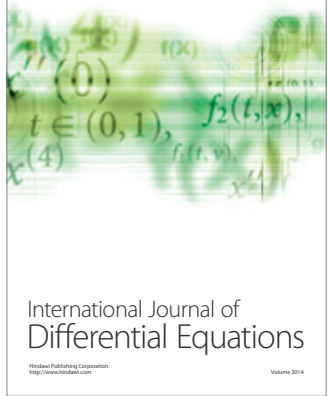
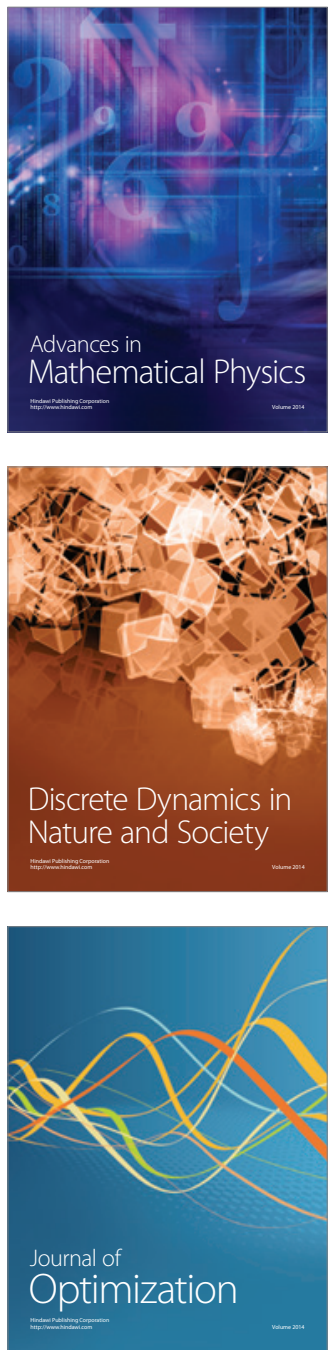